University of Nebraska - Lincoln

DigitalCommons@University of Nebraska - Lincoln

$9-11-2020$

\title{
A Historical Perspective on the Holcomb Fire: Differences and Similarities to the COVID-19 Situation and other Significant Market Events
}

Elliott James Dennis

University of Nebraska - Lincoln, elliott.dennis@unl.edu

Follow this and additional works at: https://digitalcommons.unl.edu/ageconfarmmgmt

Part of the Agribusiness Commons, Entrepreneurial and Small Business Operations Commons, Management Information Systems Commons, Meat Science Commons, Other Business Commons, and the Other Economics Commons

Dennis, Elliott James, "A Historical Perspective on the Holcomb Fire: Differences and Similarities to the COVID-19 Situation and other Significant Market Events" (2020). Extension Farm and Ranch Management. 48.

https://digitalcommons.unl.edu/ageconfarmmgmt/48

This News Article is brought to you for free and open access by the Agricultural Economics Department at DigitalCommons@University of Nebraska - Lincoln. It has been accepted for inclusion in Extension Farm and Ranch Management by an authorized administrator of DigitalCommons@University of Nebraska - Lincoln. 


\title{
A Historical Perspective on the Holcomb Fire: Differences and Similarities to the COVID-19 Situation and other Significant Market Events
}

\author{
Dr. Elliott Dennis, Assistant Professor, Livestock Marketing Economist, Department of \\ Agricultural Economics, University of Nebraska - Lincoln
}

On August 9, 2019, a fire occurred at a Tyson Fresh Meats (C) owned beef packing plant in Holcomb, Kansas. The fire mainly damaged the plant's electrical system requiring the plant to close for four months while needed repairs were completed. The plant reopened the middle of December. This plant is the second-largest beef packing plant in the United States, harvesting 6,000 head per day or approximately 6 percent of total daily beef slaughter. This event, commonly referred to as the 'Holcomb Fire,' caused numerous supply chain issues resulting in beef pricing, marketing, and placement patterns never before seen. The purpose of this article is an attempt to explain the market impacts that occurred along the supply chain. By so doing, I hope to provide some comparisons to the current COVID-19 situation and draw some implications for future similar issues.

Fundamental to this analysis/explanation are the assumptions that 1) market prices are determined by the intersection of the supply and demand for products, 2) markets are competitive resulting in agents/producers being price takers, 3) retail meat demand is passed down from consumers to producers, and 4) agents/producers desire to maximize profit. These assumptions are typical, working, and well-founded assumptions in market economics of which the meat complex is generally thought to be a part of. Most of the criticism surrounding the Holcomb Fire, COVID-19, and future incidents is/are likely a result of disagreeing with one or more of these assumptions. For example, the USDA investigation, advocated for by some market participants, is fundamentally about whether the feeder-packer and packer-retailer market are competitive or if packers can charge 'non-competitive' prices - a deviation of assumption (2). I believe it is important to state these assumptions prior to this analysis to be clear and transparent but also to recognize that differences of opinions are likely a result of disagreeing with at least one of these four underlying assumptions. Assuming the reader is comfortable, or at least willing to entertain these assumptions, then the following analysis will hopefully be both insightful and challenging. As always, I welcome all comments and feedback.

\section{Market Size and Scale Matter}

Packing plants desire to increase the daily number of cattle harvested to lower/spread out the plants fixed costs (i.e., plant infrastructure, machinery, technology, etc.). This concept is known as 'economies of scale' and is the reason large packing plants have replaced smaller plants over time and will likely continue to do so in the future. Current economic research suggests that there are still large incentives for packing plants to increase daily harvest capacity to capture additional economic profits. Of course, there are constraints on a plant's ability to increase daily capacity. Some of the major constraints include the supply of available fat cattle, competing packing plants, and labor availability. 
Once plant capacity is established, plants must run at a certain level of capacity to cover these fixed costs. 'Plant utilization' is the metric commonly used to determine how well the industry is currently using available capacity. It is calculated as the ratio between the observed level of harvest on a given day and the industry total harvest potential on a given day. Total harvest potentially is plant-specific and assumes a certain chain speed and generally two working shifts. This ratio is normally between zero and one but can be greater than one if plants run more shifts on weekdays or run weekend shifts.

Figure 1 plots the monthly average of plant utilization derived from daily observed federally inspected beef slaughter and yearly reported plant capacity. In the weeks prior to the fire, U.S. plant capacity was already running between 83-85 percent. Adding in non-inspected cattle slaughter generally pushes that number towards 90-95 percent of capacity. In other words, on average, plants across the U.S. were already running at high levels to process all available fed cattle. Shortly after the fire, the monthly average of packing plant utilization slightly dipped. Some daily plant utilization was lower, but on average, over August and September, monthly average plant utilization was relatively unchanged. Now compare this to plant utilization from COVID-19 when a large number of packing plants slowed production or completely shut down (see Figure 1). The industry lost about 20-25 percent of plant utilization in March 2020 and April 2020. Plant utilization has once again increased as plants have implemented physical distancing protocols and other CDC and OSHA recommended worker safety protocols. In summary, the biggest difference between the Holcomb Fire and the COVID-19 situation was that Holcomb was one isolated plant, whereas COVID-19 involved geographically clustered shutdowns making it much more difficult to process market market-ready fat cattle immediately.

\section{Explaining the Fundamental Market Reactions}

Packing plants lie at the intersection of two market segments. They supply wholesale beef to retailers and restaurants, and they demand fed cattle from cattle feeders to process into wholesale beef. The loss of 6 percent of processing capacity caused two primary and two secondary market reactions. The first primary reaction is that it reduced the available supply of meat for retailers to purchase, causing wholesale beef prices to rise. Rising wholesale beef prices led to the first secondary reaction. The plant fire happened on August 9, approximately one month prior to Labor Day - one of the largest grilling days of the year. Retailers had already set their meat promotion and advertisement schedule in preparation for Labor Day. As wholesale prices rose and with a plausible threat of reduced meat supplies, retailers rushed to fill orders to ensure an adequate retail meat supply for consumers. This surge in demand for wholesale beef caused the wholesale price of beef to rise further.

The second primary reaction is that the lack of capacity created an "oversupply/surplus" fed cattle market situation. In other words, given the available capacity, there were too many animals to process leading to the second secondary reaction of packer decreased demand for fed cattle to harvest. Both reactions caused fed cattle prices to decrease. This decrease in fed cattle price was ultimately passed on to feeder cattle prices as cattle feeders did not have as many intentions to feed out feeder cattle.

\section{Market Participant Assumptions}


The two primary concerns that kept fed, and ultimately feeder, cattle prices low were 1) when the packing plant would reopen and 2) whether plants could redistribute available market ready fed cattle. There was no immediate response from Tyson Fresh Meats (c) about the potential reopening of the packing plant. The last plant fire on Dec. 26, 2000, at ConAgra Beef Co.'s Garden City, Kansas, beef plant resulted in the plant never reopening. Markets adjusted to the perceived possibility that the excess supply and lack of packer demand for fed cattle could be long term. However, at the middle to end of October 2019, Tyson Fresh Meats (C) announced the plant would be rebuilt with an eventual opening by the end of 2019. The second market assumption was that remaining plants would be unable to process all current market-ready cattle and future cattle already on feed over the next 3-4 months. The only way to process this "excess supply / surplus" was to run longer shifts, increase chain speeds, or more shifts on weekends. The concern was whether plants could do this and, if so, for how long.

\section{Feeder, Live, and Boxed Beef Price Reactions}

Prices were likely affected by these and other market conditions. Thus, any changes in prices were then a result of changes in the two market assumptions a) long-term lack of capacity and b) short-term ability to process available fat cattle. Based on this, we should expect wholesale beef prices to rise and feeder and fed cattle prices to fall in the short-term. Moreover, if the two market assumptions were modified, then the long-term impact on prices should dampen or even correct for the short-term price movements. In both cases, how much prices changed is of importance as the magnitude of change matters.

Figure 2 plots the daily nearby feeder and fed cattle contract (CME 2020) and daily Choice 600-900 lbs. Boxed Beef prices (USDA-AMS 2020) pre and post-Holcomb Fire as a percent of prices on the day of the fire. Wholesale beef prices were trending downwards prior to the fire. Over the next two weeks, wholesale prices rose approximately 10 percent but returned to prefire levels by Labor Day. Interestingly, wholesale prices continued to fall post-fire but followed seasonal patterns. This suggests that wholesale prices pre-fire was higher than both 2018 and the 3-year average by about \$10-15 per cwt. Fed cattle prices were trending sideways pre-fire and dropped about 7 percent the first two weeks post-fire. After actual slaughter numbers were reported, it showed that through additional weekday and weekend shifts, plants were able to mostly make up the lost capacity. Markets responded by increasing prices to nearly pre-fire levels. However, lack of information from Tyson Fresh Meats (c) about whether the plant would reopen, and if so, how soon, caused some market participants to question whether plants could maintain these production levels long term. As a result, live cattle prices fell.

When Tyson released their intention to rebuild the plant and that the plant would likely open by the end of 2019, live cattle prices began to rise with the nearby live cattle futures prices ending 15 percent higher than pre-fire levels. Feeder cattle futures prices tracked the changes in live cattle futures prices immediately post-fire but recovered to pre-fire levels one month later. The long-term impact on the nearby feeder cattle futures appears to be minimal. In summary, for wholesale beef, live cattle futures, and feeder cattle futures, the impacts from the Holcomb fire were immediate and short-term rather than delayed and long(er)-term.

\section{Changes in Local Cash Price and Price Differentials Across Market Location}


One of the criticisms of using futures prices for this explanation is that although the Holcomb, KS plant accounted for 6 percent of daily capacity, it was a regionally isolated event. In other words, the impact on the local cash price in Kansas is likely larger than the impact on the Nebraska cash price. Table 1 tests this assumption and displays the change in prices for a weighted average of steer and heifer weekly prices relative to the prices received for cattle the week ending August 11, 2019 for Kansas, Nebraska, lowa/Minnesota, and the 5-area average. The average decrease in fed cattle prices was $\$ 11 /$ cwt regardless of location, translating to about a 9-11 percent decrease in overall price depending upon the region. The numbers in red indicate that the percent change in prices for the current week was lower than the previous week; green indicates that the change in prices was higher than the previous week. This gives a visual indication of the direction and turning points in prices. Regardless of location, local cash prices turned the week ending September 22, 2019.

Interestingly, the largest price decreases came in Nebraska rather than Kansas, where the fire occurred. Similarly, price recovery occurred quicker and with greater magnitude in Kansas compared to the other fat cattle locations. This is largely since Kansas prices were \$3-5 per cwt. lower the week of the fire. Thus, the rate of change in prices relative to this week was larger. Nominal prices received for fat cattle the week ending December 29, 2019 was approximately \$122 per cwt. regardless of location.

Price differentials are another method to look at the variation in price across space and time. Table 2 displays the weekly differences in prices for the different locations. Prior to the Holcomb fire, there were large price differentials. For example, the price difference between Kansas and IA/Minn. was $\$ 4 / \mathrm{cwt}$. After the fire, prices across space tended to converge towards each other beginning the week ending September 1, 2019. Price differentials generally stayed within \$1 per cwt. after the last week in September. Thus, there appears to be little evidence that the Holcomb Fire caused price differentials across space. Rather, there appears to be some evidence that prices converged towards one another post-fire. Combining this information with price changes by location provides little descriptive evidence that the Holcomb Fire caused changes in price differentials or market recovery across different locations.

\section{Comparing the Holcomb Fire to Other Market Shocks}

Market shocks such as the packing plant fire in Holcomb, KS are not predictable but tend to have large market movements. Since the beginning of 2019, there appeared to be quite a few of these unpredictable and large market-moving events. The 'Bomb Cyclone' in Nebraska, which caused large cattle death loss and flooding in Nebraska, the BSE cases in Washington, and COVID-19 across the world with Midwest packing plant closures have all appeared to have large impacts on market prices. The question then is, 'did all these events have a similar impact on fed and feeder cattle prices?' and 'how does the Holcomb Fire compare to these other market-moving events?'.

To answer this question, I examine the daily nearby fed and feeder cattle futures contract 20 days prior to the market event and examine price movements for 80 days post-market event. Four events are used: BSE in December 2003, Bomb Cyclone/Flooding in March 2019, Holcomb Fire in August 2019, and COVID-19 in February 2020. Figures 3 and 4 plot the percentage change in the daily feeder and live cattle futures contract relative to the price the day of each event. BSE had a more immediate impact on prices than COVID-19 or the Holcomb Fire. Feeder cattle prices took 80 trading days before recovering to pre-BSE levels compared to 22 trading days for the 
Holcomb Fire. Due to the uncertainty of government shutdowns, quarantine restrictions, and packing plant closures feeder and fed cattle prices post COVID-19 were much more volatile compared to the other three market shocks. After 80 trading days (June 20, 2020), both feeder and fed cattle prices had not fully recovered to pre-COVID-19 levels. The market reactions to the Bomb Cyclone are slightly different than the other three market shocks since it effectively reduced the supply of cattle. The other events created market situations where a 'surplus' of cattle occurred. The dip in prices for both feeder and fed cattle prices post-Cyclone/Flooding was due to the uncertainty in corn planting and harvest raising corn prices, decreasing the demand for live and feeder cattle.

These four events demonstrate how market shocks can impact both feeder and fed cattle prices. It further highlights how long-term the COVID-19 market conditions have been relative to other 'major' market impacts that have impacted the cattle industry in the last 20 years. For example, on average, COVID-19 has depressed prices 10 percent more 80 days post-market shock than BSE (arguably the largest market shock ever experienced by the industry). Other events, such as the 2015 drought and US-China Trade War, could have been used to compare with the Holcomb Fire but were omitted. The recent packing plant closures due to COVID-19 provide the best comparison since the impact has to do largely with a lack of packing capacity and changes in retail/restaurant demand.

Geographically clustered plant closures are one of the primary reasons why COVID-19 price impacts have being felt so much longer. The Holcomb Fire was one plant in one location. This allowed cattle to be shipped to different regions where there was an ability to increase plant utilization. For example, two weeks post-fire weekly reported slaughter was only 1,000 head less than the previous year. Ultimately over several weeks and months, the small backup in cattle was sorted through. However, COVID-19 plants closed around the same time and in a relatively small geographical region, creating market barriers to ship cattle to other plants. Plants that did stay open operated at lower daily capacities due to employee absenteeism, employees being sick, and implementation of lower chain speeds due to new recommended CDC and OSHA health guidelines. Combined, this created a situation where the packing plant profit-maximizing decision was to try and increase packing capacity in geographical regions rather than ship cattle longer distances. In some cases, the option to ship cattle was not even available. This regional build-up of supply decreased local cash prices until packing plants could reopen, many with reduced levels of daily slaughter. So, while the feeder and live cattle contracts reached contract lows shortly after the Holcomb Fire, the packing plant disruptions have been larger for COVID-19, translating into even lower contract lows.

\section{Changing Preferences in Price Discovery Mechanisms}

Both the Holcomb Fire and COVID-19 resurfaced concerns about price discovery, thinly traded markets, and the role of Alternative Marketing Arrangements, commonly referred to as AMA's, in the fed cattle market. During both the Holcomb Fire and COVID-19 pandemic negotiated cash fed cattle sales decreased in Nebraska but stayed relatively constant Nationwide. During Formula sales during May 2020 decreased from $70 \%$ of sales nationwide to $48 \%$ but rose in Nebraska from $40 \%$ to $70 \%$. Levels have since risen back up to near $70 \%$ in June and July 2020 nationwide. The decrease in formula sales nationwide were almost entirely replaced by negotiated grid sales in Kansas. 
Negotiated grid purchases increased in Kansas as part of a larger effort to address the concerns about thin markets and AMA's role. This led to the U.S. Senate proposing a law that would mandate large-scale packers to procure a minimum of 50 percent of total cattle purchased in the cash market each week - commonly referred to as the ' $50-14$ ' or ' $14-50$ ' rule. The assumption is that by increasing negotiated cash trade it will solve issues with price discovery effectively increasing negotiated cash prices. The supply of live cattle and demand for wholesale beef from packers determines the observed price of live cattle. To increase live cattle prices, the '50-14' rule would either need to reduce the supply of live cattle or increase the demand for wholesale beef. While the rule would increase negotiated cash transactions helping in price discovery in a given week, it is unlikely to affect the underlying live cattle market supply and demand conditions to effectively increase cash price levels. The two solutions offered by industry participants ('bid-the-grid' and the 'set-aside' program) may help reduce the cattle backlog due to packing plant closures but remains to be seen how it effectively changes underlying supply and demand conditions.

\section{Summary}

As the industry has just marked the one-year anniversary of the Holcomb fire, it has given us an opportunity to reflect on what happened, why markets reacted the way they did, identify important market assumptions that played out and compare these with other historical market shocks. In both the Holcomb Fire and the more recent COVID-19 pandemic packing plant capacity and retail demand has been impacted. This has led to decreased fed and feeder cattle prices and increased wholesale beef prices and ultimately higher gross packing margins.

This article focused on examining the short- and long-term impacts of this and other market events on prices at the national and local levels. In all cases, there were large short-term impacts. However, regardless of market shock examined, prices returned to pre-event levels generally within 4-6 months. Price differentials were likewise short-term with minimal long-term disruptions. Short-term impacts can have a large impact upon cattle feeding profitability in a low and varying margin business. The packing plant fire in Holcomb, KS as well as the recent COVID19 events have once again brought to the forefront the need to aggressive and systematically offset price risk through the use of currently available risk management tools.

\section{Post USDA-AMS Report Release}

Shortly after this report was written, the USDA Agricultural Marketing Service (USDA-AMS) released their much-anticipated report. Their objective was to assess whether price manipulation, collusion, restriction of competition, or other unfair practices occurred. This report, requested by the Secretary of Agriculture, was largely in response to producer and industry group petitions after seeing boxed beef and dressed cattle price spreads dramatically increase after the Holcomb Fire and COVID-19 packing plant closures. The released report (see https://www.ams.usda.gov/sites/default/files/media/CattleandBeefPriceMarginReport.pdf for the complete report) provided a summary of how Holcomb Fire and COVID-19 impacted boxed beef and fed cattle marketing and does NOT examine potential violations of the Packers and Stockyards Act. Overall, the USDA-AMS summary of "findings thus far do not preclude the possibility that individual entities or groups of entities violated the Packers and Stockyards Act during the aftermath of the Tyson Holcomb fire and the COVID-19 pandemic" (p. 15). If USDA- 
AMS does discover price manipulation, they will be required to report the violation to the Department of Justice (DOJ) for prosecution. Given the spotlight this has taken in recent years, it is hard to see how this would be the final ending to the investigation. 
Tables

Table 1. Percent Change in Fat Cattle Prices Pre and Post Holcomb Fire by Area Relative to Prices the Week of the Fire (USDA-AMS 2020)

\begin{tabular}{|c|c|c|c|c|}
\hline Date & Kansas & Nebraska & IA/Minn. & 5-Area \\
\hline Jul 7, '19 & -0.50 & 0.27 & -0.92 & -0.36 \\
\hline Jul 14, '19 & 2.24 & 1.26 & 0.52 & 1.13 \\
\hline Jul 21, '19 & 1.36 & 0.55 & 0.78 & 0.81 \\
\hline Jul 28, '19 & 2.27 & 1.73 & 1.47 & 1.47 \\
\hline Aug 4, '19 & 1.34 & 0.95 & 1.20 & 1.40 \\
\hline Aug 11, '19 & 0.00 & 0.00 & 0.00 & 0.00 \\
\hline Aug 18, '19 & -4.12 & -5.59 & -4.87 & -4.96 \\
\hline Aug 25, '19 & -3.32 & -4.32 & -3.66 & -4.54 \\
\hline Sep 1, '19 & -6.04 & -6.56 & -5.19 & -5.98 \\
\hline Sep 8, '19 & -8.82 & -11.17 & -8.85 & -9.62 \\
\hline Sep 15, '19 & -9.13 & -11.40 & -11.24 & -10.90 \\
\hline Sep 22, '19 & -7.51 & -9.36 & -10.06 & -9.38 \\
\hline Sep 29, '19 & -4.38 & -6.15 & -8.07 & -6.56 \\
\hline Oct 6, '19 & -2.27 & -3.90 & -5.77 & -4.33 \\
\hline Oct 13, '19 & -0.12 & -2.65 & -4.38 & -2.99 \\
\hline Oct 20, '19 & -1.38 & -2.68 & -3.18 & -2.36 \\
\hline Oct 27, '19 & 0.42 & -2.06 & -3.24 & -2.16 \\
\hline Nov 3, '19 & 2.38 & 1.28 & -0.83 & 0.66 \\
\hline Nov 10, '19 & 4.20 & 1.59 & 0.80 & 1.67 \\
\hline Nov 17, '19 & 5.01 & 2.21 & 1.11 & 2.21 \\
\hline Nov 24, '19 & 5.88 & 2.99 & 1.62 & 2.86 \\
\hline Dec 1, '19 & 8.10 & 5.42 & 3.02 & 4.85 \\
\hline Dec 8, '19 & 8.69 & 5.11 & 4.14 & 5.31 \\
\hline Dec 15, '19 & 8.65 & 5.84 & 4.64 & 5.79 \\
\hline Dec 22, '19 & 9.57 & 6.95 & 5.58 & 6.73 \\
\hline Dec 29, '19 & 11.40 & 8.15 & 7.54 & 8.47 \\
\hline
\end{tabular}

Table 2. Price Differentials in Fat Cattle Prices Pre and Post Holcomb Fire between Areas (USDA-AMS 2020)

\begin{tabular}{lcccccc}
\hline Date & KS-NE & KS-IA/MN & KS-5Area & NE-IA/MN & NE-5Area & IA/MN-5Area \\
\hline Jul 7, '19 & -4.13 & -4.03 & -3.41 & 0.10 & 0.72 & 0.62 \\
Jul 14, '19 & -2.23 & -2.67 & -2.09 & -0.43 & 0.14 & 0.58
\end{tabular}




\begin{tabular}{lllllll} 
Jul 21, '19 & -2.41 & -3.94 & -2.70 & -1.52 & -0.28 & 1.24 \\
Jul 28, '19 & -2.75 & -3.72 & -2.44 & -0.98 & 0.30 & 1.28 \\
Aug 4, '19 & -2.88 & -4.43 & -3.39 & -1.55 & -0.51 & 1.04 \\
Aug 11, '19 & -3.28 & -4.53 & -3.27 & -1.25 & 0.00 & 1.26 \\
Aug 18, '19 & -1.49 & -3.49 & -2.19 & -2.00 & -0.71 & 1.30 \\
Aug 25, '19 & -2.04 & -3.99 & -1.79 & -1.96 & 0.24 & 2.20 \\
Sep 1, '19 & -2.49 & -5.22 & -3.14 & -2.73 & -0.65 & 2.08 \\
Sep 8, '19 & -0.33 & -4.09 & -2.08 & -3.77 & -1.75 & 2.02 \\
Sep 15, '19 & -0.42 & -1.72 & -0.98 & -1.30 & -0.56 & 0.74 \\
Sep 22, '19 & -0.94 & -1.28 & -0.92 & -0.34 & 0.02 & 0.36 \\
Sep 29, '19 & -1.13 & -0.12 & -0.67 & 1.01 & 0.46 & -0.55 \\
Oct 6, '19 & -1.35 & -0.43 & -0.87 & 0.93 & 0.48 & -0.45 \\
Oct 13, '19 & -0.41 & 0.34 & -0.03 & 0.76 & 0.38 & -0.38 \\
Oct 20, '19 & -1.77 & -2.42 & -2.12 & -0.65 & -0.35 & 0.29 \\
Oct 27, '19 & -0.49 & -0.37 & -0.37 & 0.12 & 0.12 & 0.00 \\
Nov 3, '19 & -2.11 & -0.97 & -1.41 & 1.14 & 0.70 & -0.44 \\
Nov 10, '19 & -0.47 & -0.85 & -0.55 & -0.38 & -0.08 & 0.30 \\
Nov 17, '19 & -0.28 & -0.31 & -0.28 & -0.03 & -0.01 & 0.03 \\
Nov 24, '19 & -0.20 & 0.07 & -0.05 & 0.26 & 0.15 & -0.12 \\
Dec 1, '19 & -0.52 & 0.90 & 0.13 & 1.41 & 0.64 & -0.77 \\
Dec 8, '19 & 0.48 & 0.27 & 0.25 & -0.21 & -0.23 & -0.01 \\
Dec 15, '19 & -0.39 & -0.34 & -0.33 & 0.05 & 0.06 & 0.01 \\
Dec 22, '19 & -0.62 & -0.41 & -0.38 & 0.21 & 0.24 & 0.03 \\
Dec 29, '19 & 0.02 & -0.64 & -0.34 & -0.66 & -0.36 & 0.30 \\
\hline Note:A p0sin & \\
\hline
\end{tabular}

Note: A positive number implies the prices are higher in the left area compared to the right. For example, -4.13 on Jul 7, '19 for KS-NE implies that prices (\$/cwt.) were lower by $\$ 4.13$ /cwt. in Kansas relative to Nebraska prices. 
Figures

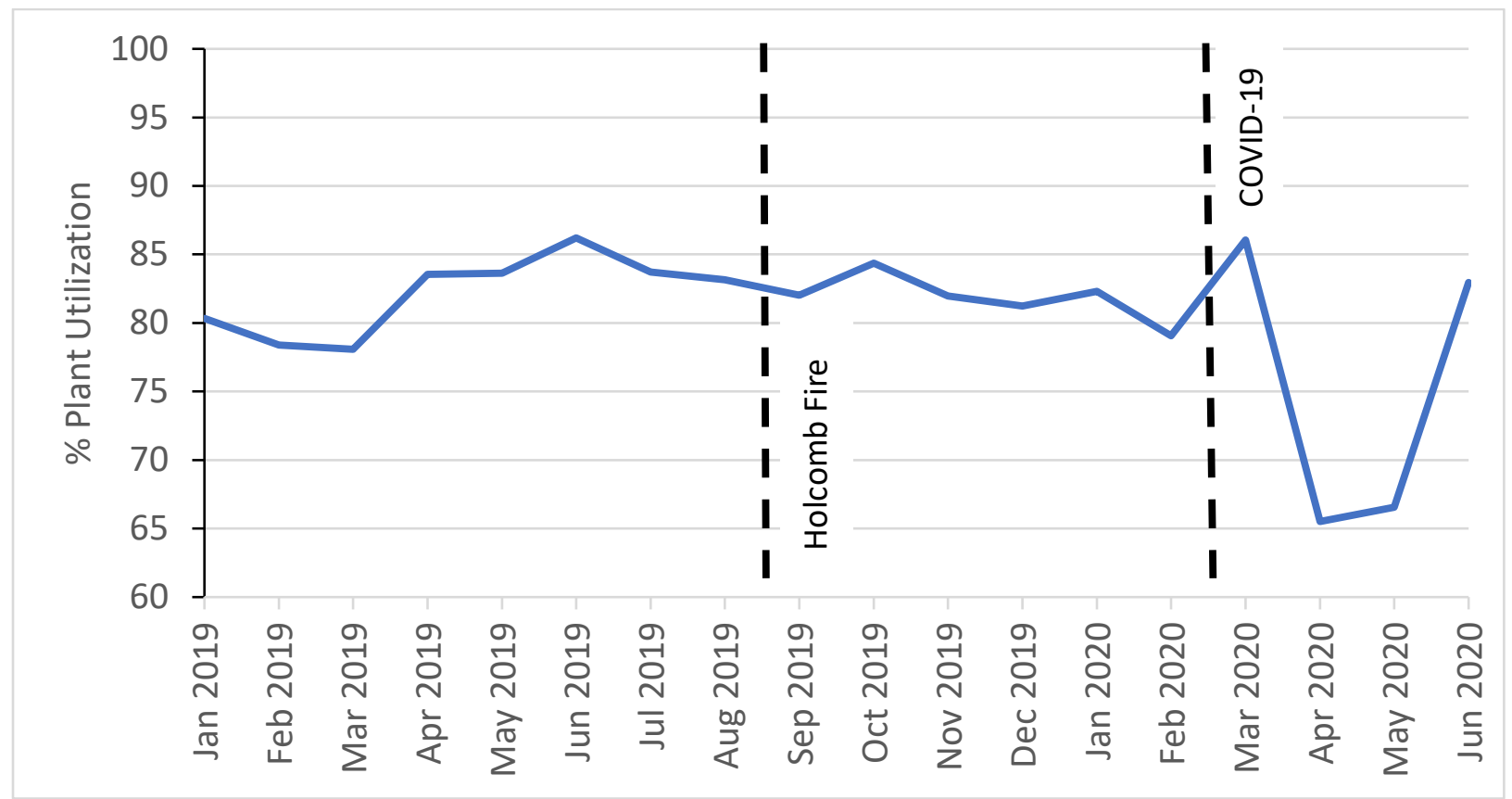

Figure 1. Monthly Averages of Daily Plant Utilization for Federal Inspected Cattle Slaughter and Yearly State Plant Maximum Capacity, Jan 2019 to June 2020

Data Source: USDA-AMS (2020); Cattle Buyers Weekly (2020) 


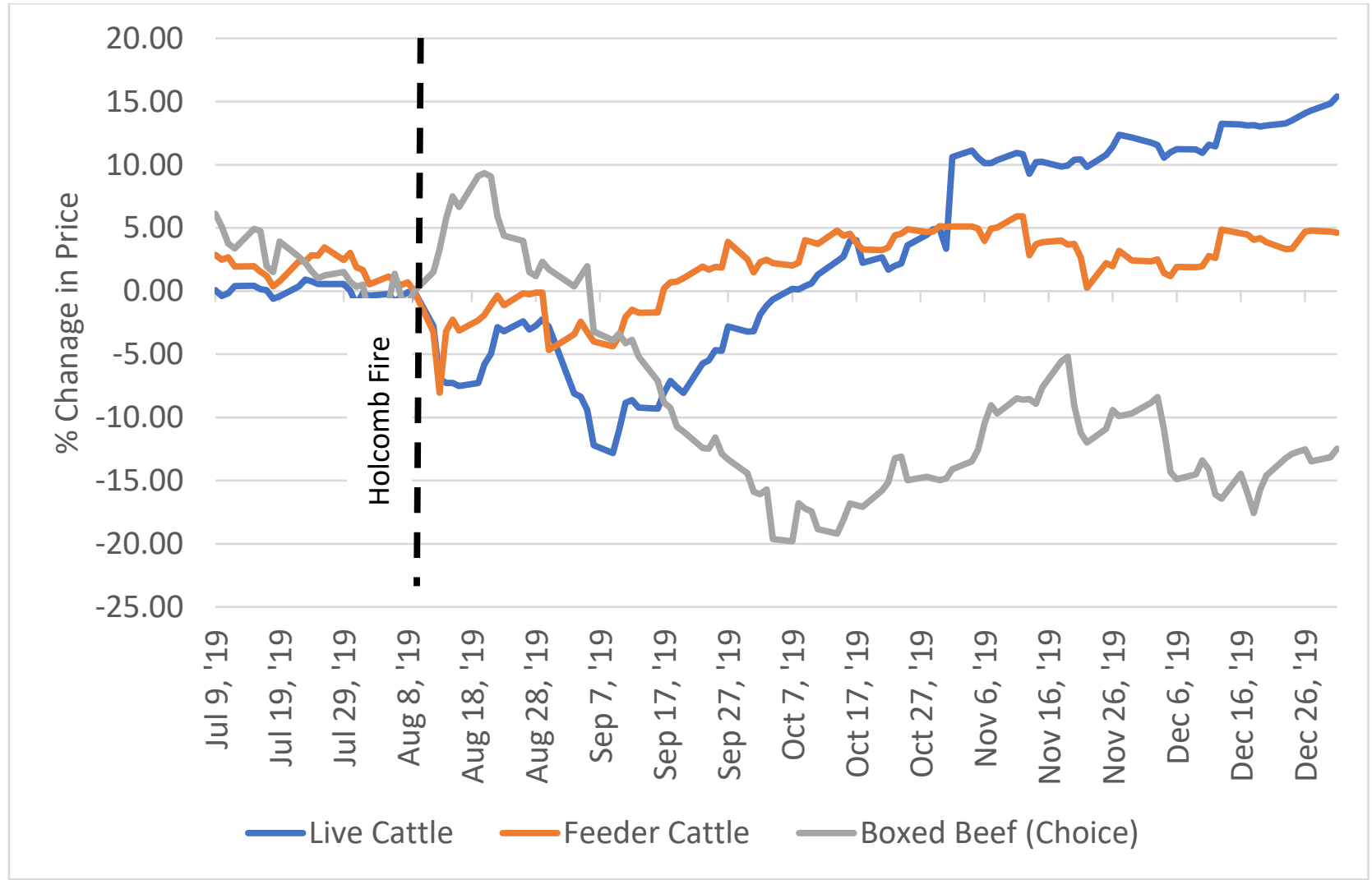

Figure 2. Percent Change in Live Cattle Futures, Feeder Cattle Futures, and Choice 600-900 lb. Boxed beef Prices Relative to Prices the Day of the Fire on August 9, 2019. Data Source: USDA-AMS (2020) 


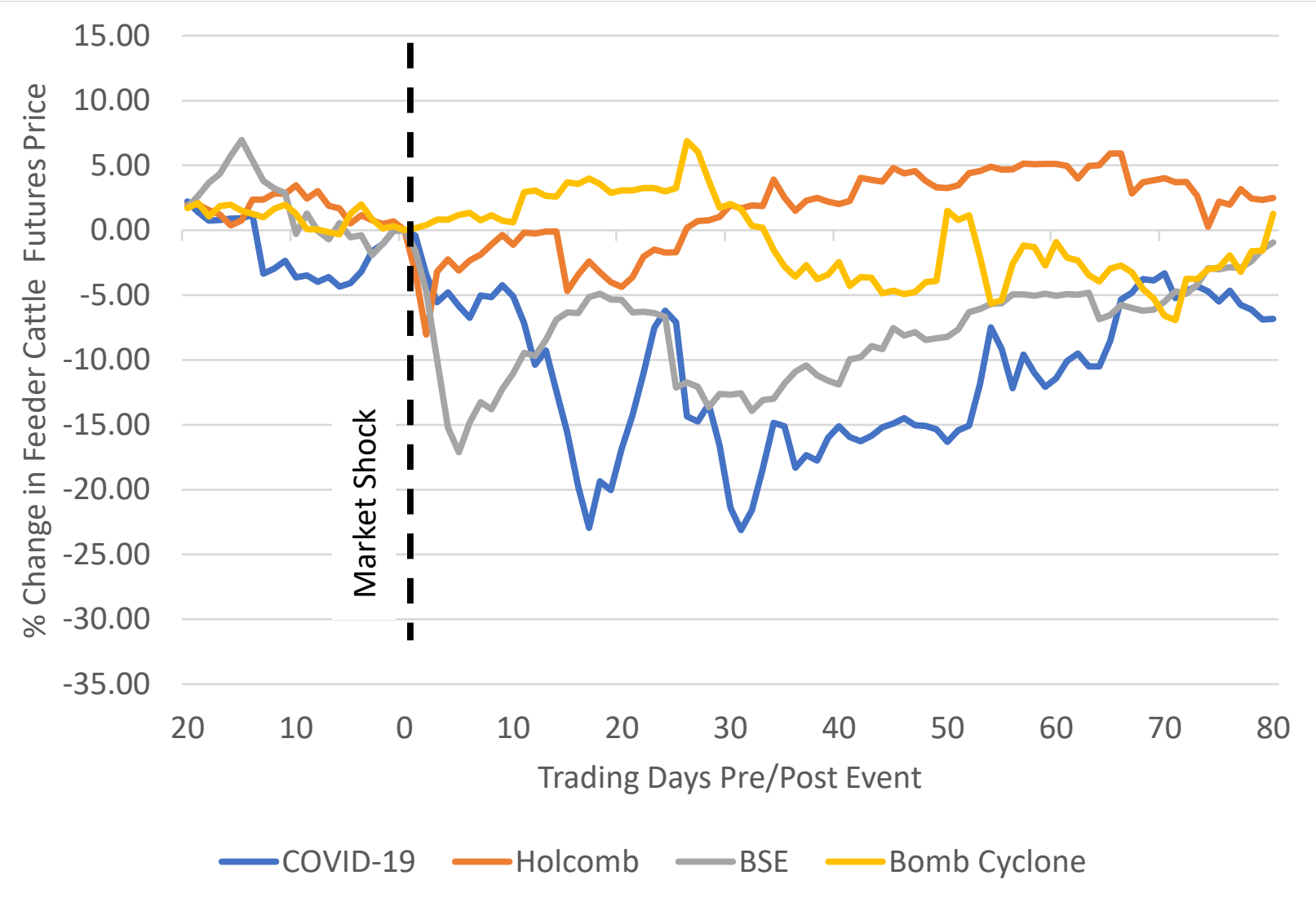

Figure 3. Percent Change in Feeder Cattle Futures Relative to Prices the Day of Event for Various Market Shocks.

Data Source: USDA-AMS (2020) 


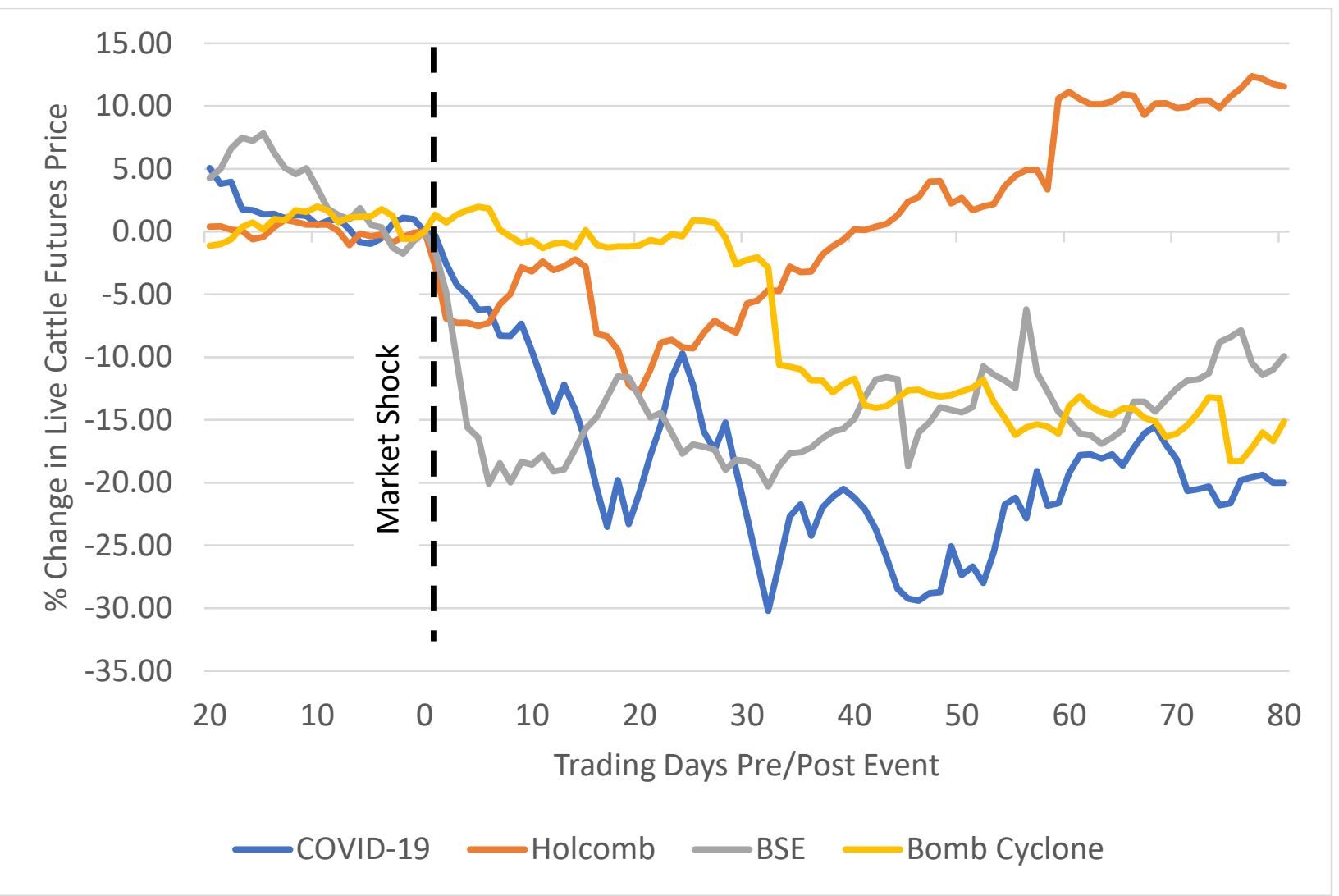

Figure 4. Percent Change in Live Cattle Futures Relative to Prices the Day of Event for Various Market Shocks.

Data Source: USDA-AMS (2020) 